\title{
Optimization under uncertainty: costs, risks and revenues Cyrus Derman memorial volume I
}

\author{
Michael N. Katehakis • Sheldon M. Ross $\cdot$ Jian Yang
}

Published online: 12 July 2013

(C) Springer Science+Business Media New York 2013

Optimization under uncertainty refers to scientific methods that are used in many different ways in a wide range of fields including statistics, economics, finance, insurance, psychology, sociology, engineering, operations, management science and information sciences. Cyrus Derman participated and played an important role in the formation of this area with his contributions, his writings and his students; as of May 2013, he has 262 descendants listed at the Mathematics Genealogy Project. A comprehensive review of his scientific contributions is provided in this volume. Initially we planned to have a single volume. However, we received so many excellent contributions that it has become necessary to publish them in two volumes. Thus, this is the first volume of a two volume series in celebration of $\mathrm{Cy}$ Derman's contributions in the field.

We would like to express our gratitude to the authors that contributed to this volume. Some of them had the good fortune to know and learn from Cy Derman. This volume would not have been possible without the anonymous contributions of the reviewers. Acknowledgments are due to Andrzej Ruszczyński and Endre Boros for their initial and continual support of the idea to do this volume. Arthur F. Veinott Jr., Uriel Rothblum and Eugene Feinberg were also sources of support. Katie D'Agosta, the journal's managing editor, worked tirelessly to assist us in all aspects of the work.

M.N. Katehakis $(\bowtie)$

Department of Management Science and Information Systems, Rutgers Business School, Newark and New Brunswick, 94 Rockafeller Road, Piscataway, NJ 08854, USA

e-mail: mnk@rutgers.edu

S.M. Ross

Department of Industrial and Systems Engineering, University of Southern California, 3715

McClintock Avenue, GER 240, Los Angeles, CA 00089-0193, USA

e-mail: smross@usc.edu

J. Yang

Department of Management Science and Information Systems, Rutgers Business School, Newark and

New Brunswick, 1 Washington Park, Newark, NJ 07102, USA

e-mail: jyang@business.rutgers.edu 